Article

\title{
The Transition to Improved Water-Related Energy Management: Enabling Contexts for Policy Innovation
}

\author{
Amanda Binks ${ }^{1, *\left(\mathbb{D}, \text { Brian Head }^{2} \text {, Paul Lant }\right.}{ }^{1}$ and Steven Kenway ${ }^{1}$ \\ 1 School of Chemical Engineering, The University of Queensland, Brisbane 4072, Australia; \\ paul.lant@uq.edu.au (P.L.); s.kenway@awmc.uq.edu.au (S.K.) \\ 2 School of Political Science, The University of Queensland, Brisbane 4072, Australia; brian.head@uq.edu.au \\ * Correspondence: amanda.binks@uqconnect.edu.au
}

Received: 16 December 2019; Accepted: 13 February 2020; Published: 17 February 2020

check for updates

\begin{abstract}
We explored the potential for improved policy and regulation with a direct focus on household water-related energy (WRE) management in urban Victoria (Australia). Semi-structured interviews were employed to understand the perspectives of relevant actors within the existing institutional landscape. In this paper, questions about institutional and policy change are addressed through consideration of the literature on transitions management and institutional entrepreneurship. Key policy opportunities identified by the actors include consumer education and advocacy for behaviour change and technology adoption, and further development of residential building standards to improve the selection and layout of building services at the design phase. The work highlights medium-term opportunities to create an enabling environment for policy practitioners in Victoria to improve management of water-related energy use in households. The work provides an important new perspective on transitions theory in the field of integrated resources management.
\end{abstract}

Keywords: water; energy; residential; transitions management; institutional entrepreneurship; integrated resource management

\section{Introduction}

Energy consumption related to water end use in Australian cities accounts for $10 \%$ of primary energy use per person, and approximately one-third of this amount occurs in households [1]. Improving the management of both water end use and energy end use has been a focus for policy and regulation, but this management effort to date has typically focused on water and energy as distinct issues. The influence of water use on energy use has not been a direct focus of policy or regulation in Australia. As a consequence, opportunities for water use management to assist with energy management have not yet been realised.

This paper explores the potential for improved policy and regulation, with a direct focus on household water-related energy (WRE) management in urban Victoria. It responds to a growing body of literature detailing the physical links between water and energy use in households, and consequent opportunities for improved management, by asking the following questions:

1. Who are the key stakeholders with an influence on water and energy end use in households, and for what reason (objective) and how (mechanism) do they exert this influence?

2. For these stakeholders, what have been the key enabling factors in past experiences of policy innovation, and what strategies have been employed? 
3. What are the views of these stakeholders on potential policy change for improved household WRE management, and in particular, the opportunities presented by a WRE policy integration focus (and likely barriers to the same)?

The aim of this paper is to highlight the medium-term work required to create an enabling environment for policy practitioners in Victoria to improve management of WRE use in households. By highlighting the experiences and perspectives of key actors within the existing institutional landscape, the work attempts to draw out the synergies and tensions within WRE management in relation to the work of policy practitioners 'on the ground'. In doing so, this work aims to lay the foundations for a policy roadmap for achieving better integration in water and related energy management.

\subsection{Background}

Urbanisation presents one of the world's most transformative trends [2]. By 2050, the world population is expected to grow by two billion people [3], and most of this growth will occur in cities. This presents many challenges, not least for the provision of basic services and for our corresponding reliance on limited natural resources. If our urban services are not efficiently designed and delivered, cities run the risk of 'locking in' increasing resource intensity as population growth and urbanisation accelerate. Climate change will compound these challenges through impacts such as resource scarcity, further compromising the adaptive capacity of our cities.

Cities also present opportunities for sustainability. They constitute the intersection where the forces which perpetuate and intensify growth (such as population, consumption, infrastructure and social needs) are clustered [4]. Recognition of the importance of the urban setting in the sustainability agenda is best exemplified in the 2016 Sustainable Development Goals, which include a strong focus on urban resilience and sustainability [5]. This focus is further highlighted in the New Urban Agenda, the multi-lateral vision for a sustainable future articulated by the secretariat of the United Nations Habitat III conference. The Agenda notes that, "if well-planned and well-managed, urbanization can be a powerful tool for sustainable development for both developing and developed countries" [2]. Our future cities offer clear potential as thriving, sustainable hubs-but efficient design and management of urban resources is a pressing challenge that must be met if we are to realise this potential.

\subsubsection{The Water-Energy Nexus: Policy Integration Challenges}

The nexus between water and energy resources has grown as a research focus, driven by recognition of the critical nature of water-energy interlinkages for economic and national security [6] and increasing resource scarcity [7-9]. The existence of a gap between water and energy management has been highlighted in research and policy [9], and a need for policies enabling coherent management between the two resource spheres is noted [7].

Integration issues in water and energy policy have consequently received increasing attention in the literature, predominantly from a high level (international, national), with a focus on examples in Australia and the US. Key findings in this literature have noted issues around fragmentation in water and energy decision making. The continued separation of water and energy policies was noted as a key challenge for effective management of water industry greenhouse gas emissions, in a systematic literature review of energy use in the water sector [9]. This analysis is supported by the work of King et al. [7], who note the diversity of roles and agencies in both water and energy management as a challenge for water-energy policy coherence, compounded by differences in hierarchies for policy making between the sectors (namely, top-down for the energy sector, and some bottom-up features for the water sector). Authors in several countries have recognised inconsistencies and opposing tendencies in water and energy management approaches $[10,11]$, stemming from a separation between the fields of environmental management, policy and regulation, and commercial water supply and wastewater treatment [9]. A need is identified for stronger cooperation and consistency between environmental targets, water supply strategy, energy efficiency and climate change policy [9]. To support this, analysts have highlighted that environmental policy needs to be capable of evaluating and integrating 
policy measures across sectors [12]. Examples of well-integrated, coherent energy-water policies are lacking, with a corresponding need for coordination in planning and in allocation of responsibilities [7]. Artioli et al. [4] note directions for future research around the question of which actors have authority and capacity for integrated management, with attention to financial, material and political resources and tools for policy change. It is also noted that the need for institutional change is likely to be ignored or resisted by key actors with power under current arrangements [13].

\subsubsection{End-Use Focus}

The urban water sector, both in Australia and internationally, has focused much attention on increasing the resource efficiency of its services. Network pressure and leakage management, combined with consumer education, rebate programs and product regulation, have significantly lowered per-capita water consumption rates. Similarly, new and emerging solutions such as waste-to-energy technologies and micro-hydro energy generation, in conjunction with enhanced efforts to optimise system operations, have contributed to managing the energy intensity of our water supplies. While such efforts endure and new solutions will continue to emerge, further efficiency gains are likely to diminish in impact once the more cost-effective options have been adopted. (In a case study of a hypothetical Australian city of population 3.4 million, Lam et al. [14] demonstrate that adoption of cost-effective utility-side options would lead to an energy saving of approximately $1300 \mathrm{GWh}$ over 20 years for water supply and sewer services. Cost-effective measures included active leak detection and repair, improving pumping efficiency, and aeration strategies.) The water sector also faces emerging resource management challenges. Developments in the water sector are intensifying the energy intensity of treatment and transfer of water [9], with growing uncertainty due to climate change necessitating adoption of alternative, often energy-intensive 'climate-resilient' water supply options, such as desalination [15]. (For example, energy use per gigalitre for water supply in Perth, Australia, increased by over 2.5 times between 2002 and 2014, following the introduction of two desalination plants in 2006 and 2011, production from which represented approximately 39\% of total Perth water supply by 2013-2014 [16]). The increasing cost of energy supply compounds such pressures [15]. Going forward, it will be important for the water sector to seek novel approaches to make further gains in the efficient management of resource use in the urban water cycle.

Integrated management of the end use of water and energy may offer significant advantages that have not yet been embraced. Recent research within Australia suggests that investment in end use options for water-related energy management (instead of utility options) could yield greater energy savings at a greater cost-effectiveness [14]. The energy use associated with urban water end use (water-related energy use, WRE) is estimated to be as much as 11 times that for water service delivery in Australia [17], half of which occurs in households. Key household WRE end-uses include showering, clothes washing, dishwashing and cooking (including water boiling) [18], with water heating for these purposes responsible for the greatest proportion of household WRE use. In Australia, water heating for these uses occurs either in a hot water system driven by gas-fired, electric or solar thermal energy, or through instantaneous electric heating within an appliance (e.g., dishwasher or washing machine).

Despite the significant potential for efficiency gains, household water-related energy use has not yet been a direct focus of management. Management of energy use through the management of water use may offer substantial efficiency opportunities to limit the resource intensity of our urban environments by maximising synergies between water and energy management, and to avoid perverse consequences through problem-shifting between the water and energy spheres. Households afford particular opportunities for management, given that they present a relatively homogenous set of water-energy end uses to be managed, and because they provide a context which is relevant to a broad cross-section of urban society. 


\subsubsection{Victorian (Australia) Household Water and Energy Regulatory and Policy Context}

Residential water and energy use in Victoria are influenced by diverse policy and regulatory agencies, with policy goals focused on water supply, energy supply, residential development and environmental sustainability. A brief overview of this policy context is provided below.

At the state level in Victoria, water and energy resources are regulated by a single state government department, with responsibilities devolved to ministries for (i) Water; (ii) Planning; and (iii) Energy, Environment, Climate Change and Suburban Development.

The ministry for Planning includes the state building authority, whose responsibilities include regulation of the state building code and local planning schemes (in conjunction with local councils). Local councils are responsible for the assessment and approval of residential development applications against the planning schemes, which include requirements for environmentally sustainable design.

The ministry for Energy, Environment, Climate Change and Suburban Development includes the oversight of a state energy efficiency incentive scheme (including a focus on domestic fittings and appliances), and a state environmental sustainability organisation.

The ministry for Water oversees a bulk water supply authority, with responsibility for treatment and supply of drinking water and recycled water, and for ensuring long-term water supply security. The bulk water supply authority provides water to three metropolitan retail water corporations (in addition to some regional retail water corporations), who supply water directly to residents and businesses.

Energy supply to households in Victoria occurs via retail energy companies. Energy is purchased by the retail energy companies from distribution network entities, who operate under operational control by a national market and system operator and under the regulation of a national energy regulator.

Price, quality and reliability of retail water and energy services are regulated by a state economic regulator.

\subsection{Conceptual Approach}

The water-energy policy problem involves multiple actors, at multiple levels, with a diversity of interests. Efforts to achieve integration in water-energy policy need to recognise the complexity of these structural issues, and any methodology applied to further the case for improved WRE management will need to be capable of addressing them. The literature on transition management for sociotechnical systems offers some guidance in this context.

Processes of institutional change have been the subject of study in the field of transitions theory. In a policy context, transitions theory focuses on pathways toward 'radical or fundamental change in government policy or public policy' [19]. Institutional change is also a core focus of the field of institutional entrepreneurship, which deals with the contribution of various actors in leading or mobilising institutional change or policy innovation [20].

This paper draws on both fields. To understand how to facilitate a transition toward policies focused on improved WRE management, this study focuses on identifying enabling conditions for institutional entrepreneurship (or policy innovation) by key actors.

Sections 1.2.1 and 1.2.2 of this paper outline the key considerations in transitions theory and institutional entrepreneurship which were drawn upon to inform this study. The way in which these considerations were synthesised to develop the approach adopted for this study is then summarised in Section 1.2.3.

\subsubsection{Sociotechnical Systems, Transitions Theory and Transition Management Considerations}

Water and related energy involve an interdependence of technical infrastructure and management systems, with both supply and user components, and multiple actors. As such, WRE use can be conceptualised as a sociotechnical system. Conceptualising WRE use as a sociotechnical system is a useful lens through which to approach WRE management, in that it accounts for relationships between supply and demand characteristics, multi-actor processes, and the inter-relatedness of 
technical and nontechnical characteristics. Sociotechnical systems are defined as clusters of elements, including technology, regulations, user practices and markets, cultural meanings, infrastructure, maintenance networks and supply networks [21]. Changes in a sociotechnical system involve not only changes in components, but changes in the structure of the system as well. In [21], the authors note that an advantage of a sociotechnical systems' focus is in highlighting the inter-relatedness of supply-and-demand characteristics, and a focus which is wider than just one industry or sector.

A shift toward improved management of WRE use can therefore be conceptualised as a transition in a sociotechnical system. The field of transition theory is concerned with the study of transitions, defined by Loorbach et al. [22] as "long-term fundamental changes (irreversible, nonlinear, multi-levelled and systemic) in the cultures (mental maps, perceptions), structures (formal institutions, and infrasystems), and practices (use of resources) of a societal system". Loorbach et al. [22] note that transitions theory has been applied to sociotechnical systems, innovation systems and complex adaptive systems, all of which have several basic characteristics in common: (a) open systems embedded in an external environment, with which they co-evolve; (b) the changing external environment influences these systems; and (c) nonlinear changes in system structure are evident in adapting to changes in the external environment.

Transitions in sociotechnical systems are commonly explained through the 'Multi-Level Perspective' (the MLP) first described by Geels [23]. The MLP describes interacting processes in a sociotechnical system, between the micro-level (the 'niche' level), the meso-level (the 'regime') and the macro-level (the 'landscape'). Niches are embedded within regimes, and regimes within landscape. The core concept of the MLP is the sociotechnical regime, defined by Loorbach et al. [24] as "a coherent, highly interrelated and stable structure at the meso-level characterised by established products and technologies, stocks of knowledge, user practices, expectations, norms, regulations, etc." At the micro-level, sociotechnical niches are the "locus for radical innovations", protected spaces which act as "incubation rooms for radical novelties" [25]. The macro-level of the MLP is the sociotechnical landscape, which encompasses the wider exogenous environment (e.g., environmental problems, cultural attitudes and economy) that is beyond the direct influence of actors in the regime, but which affects sociotechnical development [25]. New approaches emerge from niches in response to problems in the existing landscape and regime, and they become available for uptake, diffusion and stabilisation at the regime level (given suitable conditions). A newly configured regime may then further influence broader landscape factors. These interactions between niches, regimes and landscapes describe the 'transition' process in sociotechnical systems.

While transitions theory is concerned with the general study of change processes in sociotechnical systems, the field of transition management is concerned with understanding how actors might influence this development to "attain desirable social objectives and avoid serious pitfalls" [26]. Transition management therefore provides a useful lens through which to approach a shift in water and energy management in urban households toward improved management of WRE use. Concepts in this field have roots in systems theory, evolutionary economics and integrated assessment. Transition management concepts can be employed to gain insight into how to "formulate governance principles, methods and tools to deal more systematically with fundamental system change" [22], and they have frequently been applied to the problem of sustainable development (e.g., Bettini et al. [27], Loorbach [28], Meadowcroft [26], Rotmans and Loorbach [29], Smith and Stirling [30], and Smith et al. [31]).

Transition management comprises several key components [26]: a transition dynamic, involving movement from one equilibrium to another; conceptualisation, using the MLP; the use of future-focused visioning and goal-setting devices (goals, visions, pathways and intermediate objectives); a focus on practical activities (arenas and experiments); and an emphasis on decision making under conditions of uncertainty, involving gradual adjustment of development pathways in line with long-term goals.

The conceptual framework of transition management faces a number of challenges: 
- Practical challenges

- There are practical challenges in developing interorganisational collaboration and shared vision. Markard et al. [32] note the highly uncertain nature of transitions processes, noting that, "even the formulation of a policy problem is ambiguous and contested, let alone policy goals, strategies and expected outcomes".

- Theoretical challenges

- Transitions academics have highlighted a dominant focus in the literature on the way in which change is stabilised and normalised at the regime level. They argue that a knowledge gap exists in understanding the interaction between niches and regimes through a transition, which produces new forms of governance [27,33,34]. It is further argued that an understanding of institutional context underlying societal transitions can assist in addressing this gap [27].

- Some critics suggest that transitions literature tends to focus on a 'teleological' treatment of successful transitions [35], without taking into account those that did not achieve success.

\subsubsection{Institutional Entrepreneurship Considerations}

Institutions are "enduring patterns of social practice" [36] within our society which are maintained by formal and informal social constraints (e.g., rules, habits, constitutions, laws and conventions) [37]. These constraints affect the behaviour of actors and organizations, or the "agents ... that have preferences and objectives" [37]. Organizations thus interact with each other and broader society within an institutional landscape, which influences their behaviour. In the context of water and energy use in cities, institutional analysis provides a way of conceptualising the way in which patterns have developed in society to manage water and energy provision and use.

The role of actors in influencing institutional change is the focus of studies in institutional entrepreneurship. In particular, institutional entrepreneurship focuses on "the activities of actors who have an interest in particular institutional arrangements, and who leverage resources to create new institutions or transform existing ones" [38]. The field of institutional entrepreneurship contrasts the normally stabilising effects of institutions, which reinforce continuity and reward conformity [38], with the creative effects of entrepreneurial activities in seeking to bring about change within those institutions and/or organisational processes. This tension between effects of stabilisation and the pressures for change is referred to in literature as the 'structure-agency paradox', which explores the way in which entrepreneurial actors can be embedded within the stabilising structures of institutions, while also being able to 'step outside' their social context and act with the resources and motivation required to change those structures [20,38]. Resolution of this paradox is necessary for institutional entrepreneurship to make an impact.

In a review of the institutional entrepreneurship literature, Leca et al. [20] identify two broad issues as central to the study of institutional entrepreneurship: (a) the conditions under which an actor is likely to become an entrepreneur, and (b) the processes through which institutional entrepreneurship unfolds. They note that a number of studies suggest that 'enabling conditions' [39] play a key role in institutional entrepreneurship, supporting actors to overcome the structure-agency paradox. They further note that the processes of institutional entrepreneurship which have received attention in the literature include the development of discursive strategies (i.e., framing an issue to highlight organisational failings and to justify change [40-43]), and the mobilisation of resources to develop those strategies for improvement [20].

The role of enabling conditions, and the processes of resource mobilisation, in institutional entrepreneurship, as identified by Leca et al. [20], were adopted as a central focus for this work. The implication is that, to begin a transition toward improved WRE management, niche actors will 
need to engage in institutional entrepreneurship to put forward new practices and approaches for adoption and stabilisation at the regime level.

\subsubsection{Synthesis of Study Approach}

Transitions theory focuses on the uptake and stabilisation of new practices, norms, etc., within an institutional field or regime (the institutional field or regime being characterised by a collection of actors who share norms, etc.). This paper takes the view that, for household WRE management to become a stronger focus for policy, a transition will be required away from current separate management approaches for water and energy use toward a more integrated approach. Such a transition is a long-term process. The essential precursor steps in this process-in which new practices emerge and become available for adoption at regime/field level-have received little attention in transitions literature. Transition management academics have highlighted a knowledge gap arising from the limited attention given to understanding how niches and regimes interact through transitions, and thereby produce new forms of governance [27,33,34]. This paper argues that, if we wish to better manage transitions, intervention at this 'niche emergence' level offers greater opportunity to influence the direction of transitions, by creating favourable conditions for emergence. Furthermore, a focus on the creation of favourable conditions for niche emergence is likely to assist subsequent adoption and stabilisation processes at regime level, by focusing on decision contexts for multiple key actors and thereby laying the groundwork for building consensus. The discussion section of this paper (Section 4) presents a discussion of study findings against this theoretical framing.

\subsection{Study Aim and Objectives}

The particular focus of this paper is on the shorter-term ways in which key actors might begin to initiate change toward household water-related energy management, as a foundation for a longer-term transition. The field of institutional entrepreneurship is drawn upon to explore the ways in which such change is being initiated. To achieve this, this paper seeks to understand the perspectives of key actors within the current institutional landscape. We particularly focus on the following:

1. Who are the key stakeholders with an influence on water and energy end use in households, and for what reason (objective) and how (mechanism) do they exert this influence?

2. For these stakeholders, what have been the key enabling factors in past experiences of policy innovation?

3. What are the views of these stakeholders on potential policy change for improved household WRE management, and in particular, the opportunities presented by a WRE policy integration focus (and likely barriers to the same)?

\section{Materials and Methods}

This study employed semi-structured interviews, focused on understanding the perspectives of relevant actors within the existing institutional landscape for household and water and energy management in urban Victoria. Audio recordings of the interviews were transcribed and thematically analysed, drawing on factors from transitions management and institutional entrepreneurship theory, to address each of the research questions for the study. Interview material also referenced outcomes of previous qualitative research on household water-energy interconnections published by the authors $[18,44]$.

This study was completed under human research ethics approval granted by the University of Queensland Engineering, Architecture and Information Technology, Low and Negligible Risk Ethics Committee (approval number 2017000659).

Methods adopted for participant selection and recruitment, the interview process and transcript data analysis are detailed in Sections 2.1-2.3 of this paper. 


\subsection{Participant Selection and Recruitment}

Participation was sought from organisations with an interest in the management of water or energy use in households in urban Victoria, with a primary focus on participants with supply side management interests. Consumers and households were not engaged in the study (however, a participant in a consumer protection policy role was included in the study). Participants were initially invited to participate in the study directly by the researcher, via phone or email, through relationships established at stakeholder workshops in earlier stages of the parent research project. The 'snowball' method [45] was then used to identify further participants of relevance to the research, upon recommendation from the initial participants. These were contacted through introduction via the recommending party.

Participants included those with an active role in influencing water and/or energy use in households, in addition to parties significantly interested in or affected by household water and/or energy use but without a direct pathway of influence on the households themselves. A range of organisations and individuals were contacted, including water utilities (bulk and retail), energy distribution and retail companies, state government departments, local governments, independent regulatory bodies, community organisations and industry professional organisations. These participants were principally from the water sector, energy sector and residential building sector, in addition to the social and environmental sectors. Participants are not a representative list of all influences, but were selected to highlight the diversity of key influences and their perspectives.

Study participants are outlined in Table 1.

Table 1. List of interview participants.

\begin{tabular}{|c|c|c|}
\hline ID & Organisation & Position Title \\
\hline A & $\begin{array}{l}\text { Local government greenhouse emissions } \\
\text { management network }\end{array}$ & Chief Executive Officer \\
\hline $\mathrm{B}$ & Water utility (retail) & Manager, Strategic Communications \\
\hline $\mathrm{C}$ & Water utility (retail) & Manager, Demand Forecasting \\
\hline $\mathrm{D}$ & $\begin{array}{l}\text { State government environmental sustainability } \\
\text { organisation }\end{array}$ & Specialist, Energy Efficiency \\
\hline $\mathrm{E}$ & Water utility (retail) & Manager, Strategic Projects \\
\hline $\mathrm{F}$ & Local council & $\begin{array}{l}\text { Senior Advisors, Environmentally } \\
\text { Sustainable Design }\end{array}$ \\
\hline G & Nongovernment social welfare organisation & Manager, Policy and Research \\
\hline $\mathrm{H}$ & Energy infrastructure business (gas) & Manager, Asset Planning \\
\hline I & $\begin{array}{l}\text { Not-for-profit climate change management } \\
\text { organisation (community focused) }\end{array}$ & $\begin{array}{l}\text { Program Manager, (emissions } \\
\text { reduction program) }\end{array}$ \\
\hline $\mathrm{J}$ & State government department & $\begin{array}{l}\text { Policy Officer, (energy efficiency } \\
\text { incentive scheme) }\end{array}$ \\
\hline K & Water utility (retail) & Specialist, Greenhouse Gas and Energy \\
\hline $\mathrm{L}$ & State economic regulator & Policy Supervisor, (energy efficiency scheme) \\
\hline M & $\begin{array}{l}\text { Industry-led training centre for sustainability } \\
\text { in trades }\end{array}$ & Chief Executive Officer \\
\hline $\mathrm{N}$ & Not-for-profit sustainable living organisation & Senior Energy Analyst \\
\hline $\mathrm{O}$ & State government department & $\begin{array}{l}\text { Senior Policy Officer, Water and Catchments } \\
\text { (Policy, Governance and Legislation) }\end{array}$ \\
\hline $\mathrm{P}$ & $\begin{array}{l}\text { Independent professional-Building } \\
\text { regulation sector }\end{array}$ & Experienced Regulatory Officer \\
\hline Q & Water utility (bulk) & Principal, Integrated Planning \\
\hline
\end{tabular}




\subsection{Interview Process}

Interviews were conducted between July and October 2017, in person (15) and over the phone (2). Each interview was between 45 minutes and 1 hour in length and was audio recorded. Where required, short follow-up phone calls were made to gather supplementary information to clarify interview responses.

Interviews were semi-structured and were conducted by the researcher as an open conversation with the participant. Interview participants were presented with outcomes of the research expressed in $[18,44]$, following which a list of questions was then used to guide the interview process toward topics of interest. These questions were adapted to suit each participant, and questions were included or excluded as appropriate to the participant's role and experience. The interview questions focused on each participant's role, professional relationships, experience of strategic planning processes, experience of change in work direction or priorities and perspectives on the potential for WRE management in households.

Audio recordings of the interviews were transcribed by the researcher and thematically analysed according to methods outlined in Section 2.3, below.

\subsection{Transcript Data Analysis}

\subsubsection{Theme 1-Key Stakeholders Influencing WRE Use, and Their Roles}

During the interviews, participants were asked to describe the role of their organisation. These responses were analysed, in conjunction with a review of grey literature focused on organisational mission statement and objectives (e.g., organisation or department charter, annual reports, statements of obligations).

The above data were then analysed to identify organisational (a) objectives and (b) mechanisms with relation to management of water or energy end use, according to the following definitions:

- Objective: the outcome an actor is seeking in influencing the system relating to water and/or energy use in households. Objectives were summarised into the following three categories, which were drawn from groupings observed in participants' responses:

- Technical—security and reliability of water and/or energy supply;

- Environmental—strategic resource management, including greenhouse gas emissions management and water use efficiency;

- Social—social welfare, including cost of living and liveable communities.

- Mechanism: the type of activity undertaken to exert influence on water and/or energy use in households. Examples include end-user education to influence behaviour, development of standards, regulation and provision of economic incentives.

Stakeholders were also grouped into two broad categories, to aid in the discussion of the results: (a) those with a direct influence on water and/or energy end use within households, (b) and those with a clear interest but an indirect influence.

\subsubsection{Theme 2-Past Experiences of Successful Policy Innovation}

During the interview, participants were asked to describe a past experience in their work where they had observed or been part of a new policy direction. These past experiences described by the participants could relate to a new policy direction in any aspect of their role and did not necessarily need to relate to water and/or energy use. The focus of the question was on experience of change processes.

The analysis of responses focused on the role of enabling conditions and processes of resource mobilisation in institutional entrepreneurship activities, as identified by Leca et al. [20] (described in Section 1.2.2). Interview transcripts were coded to identify the following factors outlined in Table 2 [20]: 
Table 2. Institutional entrepreneurship factors adopted for transcript analysis.

\begin{tabular}{|c|c|c|}
\hline \multicolumn{2}{|c|}{ Factor } & \multirow{2}{*}{$\begin{array}{l}\text { Description } \\
\text { Precipitating jolts or crises, e.g., social upheaval, } \\
\text { technological disruption, competitive discontinuities and } \\
\text { regulatory changes } \\
\text { Acute, field-level problems which might precipitate } \\
\text { crises, e.g., scarcity of resources }\end{array}$} \\
\hline Enabling context & Field-level conditions & \\
\hline & Individual-led conditions & Organisational internal leadership, organisational culture \\
\hline \multirow[t]{2}{*}{ Resources mobilised } & Intangible resources & $\begin{array}{l}\text { Social capital: position in a web of social relations that } \\
\text { provide information and political support, and ability to } \\
\text { draw on that standing to influence others' actions } \\
\text { Legitimacy: the extent to which an author's actions and } \\
\text { values are viewed as congruent with values and } \\
\text { expectations of greater environment } \\
\text { Formal authority: legitimately recognised right to } \\
\text { make decisions }\end{array}$ \\
\hline & Tangible resources & $\begin{array}{l}\text { Financial assets } \\
\text { Information, skills and expertise }\end{array}$ \\
\hline
\end{tabular}

\subsubsection{Theme 3-Perspectives on Improved Household WRE Management}

Participants were talked through the research outcomes published in [18,44]. Binks et al. [18] present a detailed analysis of WRE end use in households in Victoria, highlighting end uses which contributed most to differences in total WRE use between individual households. Building on this work, Binks et al. [44] present a policy scenario analysis identifying the potential scale of opportunity for WRE savings through a shower-water-demand management program. Participants were asked to comment on the relevance of the findings presented in [18,44] to their work (if any), their views on what opportunities they saw WRE management presenting (generally, not limited to their work) and what barriers might need to be overcome. Responses were grouped according to common themes and then summarised.

\section{Results}

\subsection{Theme 1-Who Influences Household WRE Use, Why and How?}

Stakeholders with both direct and indirect influences on household WRE were interviewed. Management objectives spanned greenhouse gas emissions management, water supply security, water efficiency, water and energy supply reliability, cost of living and social welfare. These objectives were achieved through mechanisms such as expert advice, information and training, advocacy, economic incentives, economic regulation and building regulation.

\subsubsection{Direct Influence on Household Water or Energy End Use}

Table 3 presents a summary of the management objectives and influence mechanisms of stakeholders with a direct influence on household water or energy end use. These findings are further discussed below. 
Table 3. Stakeholders with direct influence-management objectives and mechanisms.

\begin{tabular}{|c|c|c|c|c|c|c|}
\hline \multicolumn{2}{|c|}{ Stakeholder } & \multicolumn{5}{|c|}{ Management Objective } \\
\hline Sector & ID & $\begin{array}{l}\text { GHG Emissions } \\
\text { Management }\end{array}$ & $\begin{array}{l}\text { Cost of Living } \\
\text { (Energy/Water) }\end{array}$ & $\begin{array}{c}\text { Social } \\
\text { Welfare }\end{array}$ & $\begin{array}{l}\text { Resource Use } \\
\text { Efficiency }\end{array}$ & $\begin{array}{c}\text { Supply } \\
\text { Security/Reliability }\end{array}$ \\
\hline \multirow{4}{*}{ Energy } & I & $\begin{array}{l}\text { Information; } \\
\text { Expert advice }\end{array}$ & $\begin{array}{l}\text { Information; } \\
\text { Expert advice }\end{array}$ & - & - & - \\
\hline & $\mathrm{N}$ & $\begin{array}{l}\text { Information; } \\
\text { Expert advice }\end{array}$ & $\begin{array}{l}\text { Information; } \\
\text { Expert advice }\end{array}$ & - & - & - \\
\hline & $\mathrm{D}$ & Information & Information & - & - & - \\
\hline & $\mathrm{J}$ & Economic incentives & - & - & - & - \\
\hline \multirow[b]{2}{*}{ Water } & $\mathrm{BCE}$ & - & Information & - & - & Information \\
\hline & $\mathrm{O}$ & - & Economic incentives & - & - & Economic incentives \\
\hline \multirow{2}{*}{$\begin{array}{l}\text { Residential } \\
\text { buildings }\end{array}$} & $\mathrm{F}$ & Regulation & - & Regulation & - & - \\
\hline & $\mathrm{P}$ & Regulation & - & - & Regulation & - \\
\hline
\end{tabular}

Energy-sector stakeholders having a direct influence on household end use were interviewed, including not-for-profit organisations (I, N), and government-run sustainability bodies (D) and energy efficiency incentive schemes $(\mathrm{J})$. The objectives of these stakeholders in engaging with household end-use issues focused on greenhouse gas emissions management ( $\mathrm{D}, \mathrm{I}, \mathrm{J}$ and $\mathrm{N}$ ) and cost-of-living issues relating to energy use (D, I and N). The mechanisms employed to achieve these objectives included the provision of expert advice ( $\mathrm{I}$ and $\mathrm{N}$ ) and economic incentives $(\mathrm{J})$ to influence technology choice, and provision of information to improve understanding of energy use issues and impacts (D, I and N). These stakeholders had a strong focus on influencing technology choice, to achieve greenhouse gas emissions management objectives.

Water-sector stakeholders interviewed with a direct influence on household water use included a water supply entity (BCE) and a state government water efficiency regulator $(\mathrm{O})$. The objectives of their work of relevance to household end use were focused on water supply security and cost of living. Mechanisms for achieving this focused primarily on provision of information targeting user behaviour $(\mathrm{BCE})$ and rebates to encourage water-efficient technology uptake $(\mathrm{O})$.

Stakeholders from the residential building and building services sector were interviewed, comprising local and state government regulatory actors ( $\mathrm{F}$ and $\mathrm{P}$ ). The objectives of these stakeholders in engaging with household end-use issues focused on environmental protection in the form of greenhouse gas emissions management $(\mathrm{F}$ and $\mathrm{P})$ and water efficiency $(\mathrm{P})$, and social welfare in the form of liveable communities (F). Regulation of physical features of residential buildings (new or renovated) was employed to achieve these aims.

\subsubsection{Indirect Influence on Household End Use}

Table 4 presents a summary of the management objectives and influence mechanisms of stakeholders with an indirect influence on household water or energy end use. These findings are further discussed below.

Table 4. Stakeholders with indirect influence-management objectives and mechanisms.

\begin{tabular}{ccccccc}
\hline \multicolumn{2}{l}{ Stakeholder } & \multicolumn{5}{c}{ Management Objective } \\
\hline \multirow{2}{*}{ Sector } & ID & $\begin{array}{c}\text { GHG Emissions } \\
\text { Management }\end{array}$ & $\begin{array}{c}\text { Cost of Living } \\
\text { (Energy/Water) }\end{array}$ & $\begin{array}{c}\text { Social } \\
\text { Welfare }\end{array}$ & $\begin{array}{c}\text { Resource Use } \\
\text { Efficiency }\end{array}$ & $\begin{array}{c}\text { Supply } \\
\text { Security/Reliability }\end{array}$ \\
\hline \multirow{5}{*}{ Energy } & A & Expert advice & - & - & - & - \\
& M & Expert advice & - & - & - & - \\
& H & - & - & - & - & Economic tariffs \\
& L & - & Regulation & - & - & - \\
\hline \multirow{2}{*}{ Water } & Q & - & - & - & - & Research \\
\hline Social & G & - & Advocacy & - & - & - \\
\hline
\end{tabular}


Stakeholders interviewed with a clear interest in WRE but an indirect influence on household water and/or energy end use issues included a nongovernment emissions advocacy network (A), a nongovernment industry skills body $(\mathrm{M})$, an energy distribution entity $(\mathrm{H})$, a nongovernment social welfare organisation $(G)$, an energy sector regulatory body (L) and a bulk water supply entity (Q). Their interests in household end-use issues included greenhouse gas emissions management (A and $M$ ), protection of affordability of essential services for households ( $G$ and $L$ ), and maintaining reliability of energy $(\mathrm{H})$ and security of water $(\mathrm{Q})$ supplies. This was achieved through influences such as advocacy $(\mathrm{G})$ and provision of expert advice and training (A and $\mathrm{M}$ ) relating to renewable energy technologies and energy management opportunities and strategies. Other influences included research and strategy development to drive water efficiency $(Q)$ through water retail entities, economic regulation (L) of energy pricing and efficiency incentive schemes, and economic influences such as energy tariff setting $(\mathrm{H})$.

\subsection{Theme 2-Past Experiences of Successful Policy Innovation}

Stakeholders recounted past experiences of policy innovation under a number of field-level and individual-level conditions (previously defined in Table 2). Field-level conditions included changes in government policy/priorities, technological/market disruption, development of industry norms and community attitudes. Individual-level conditions included organisational leadership and a strong sense of organisational role within the community. These outcomes are discussed in Sections 3.2.1 and 3.2.2.

Resources mobilised in these experiences of policy innovation, and the strategies employed for mobilising them, are discussed in Sections 3.2.3 and 3.2.4.

\subsubsection{Field-Level Context}

Change in government priorities and/or specific new government policies were the most common field-level conditions referenced as underpinning policy innovation ( $B, D, E, J, K, M, N, P$ and $Q)$. Shifting policy priorities following a change of state government were noted as instrumental to new energy-related policy initiatives in both the energy sector (D, J, M, N and P) and water sector (K). These came about as a response to an increased federal government focus on emissions ( $\mathrm{D}, \mathrm{M}$ and $\mathrm{P}$ ), followed by a shift of state government priorities to a focus on cost-of-living concerns, with a change in state political leadership ( $\mathrm{J}$ and $\mathrm{N}$ ). In terms of specific government policies, the state government Water for Victoria strategy was referenced by participants in the water industry (B, E and Q) as providing impetus for initiatives beyond the scope of traditional water sector operation. Similarly, a new state government water efficiency strategy was also noted (Q) as underpinning new approaches to cost-benefit analysis of water efficiency programs.

Technological and market disruptions were noted by energy-sector stakeholders (A, D, I and J) as key factors in policy innovation. This was noted in examples of policy formed in response to increasing solar PV penetration disrupting energy markets, increasing cost of energy and rapid population growth changing residential development profiles. In case A, the disrupted nature of energy markets was seen as an opportunity to participate in distributed energy generation activities to both safeguard against growing costs and to further greenhouse gas emissions reduction goals (the purpose of the organisation). Rapid population growth and corresponding growth in greenfield development was leveraged as an opportunity for targeted residential energy efficiency initiatives (D). The intersection of growing energy cost concerns and increased availability of battery storage was seen as an opportunity for medium-scale rooftop solar PV programs in a highly developed area (I). Similarly, growing energy cost concerns provided impetus for a residential energy efficiency program (J).

The development of industry norms was also noted as a driver for policy innovation, by stakeholders in the residential building regulation and energy sectors $(\mathrm{F}, \mathrm{H}$ and $\mathrm{P})$. Emergence and maturation of environmentally conscious planning approaches to regulation of residential development were cited as a driver for new council policy (F). Similarly, changes in the national construction code were noted as underpinning changes in state regulation $(\mathrm{P})$. New risk-based asset management 
standards developed by the peak energy industry regulator were also noted as a trigger for changes in asset renewals approach in the energy distribution sector $(\mathrm{H})$.

'Green' concerns held by local council constituents were cited as a supporting factor in development of new sustainability policy for regulation of residential development (F).

\subsubsection{Individual-Level Conditions}

Leadership was noted as an important factor in case BCE. Stakeholders from a water-sector entity highlighted strong leadership from their CEO in setting a vision and mandate for 'breakthrough performance'. This was accompanied by deliberate training and soft skills development within the organisation to build the capacity of staff to innovate, driven primarily through intensive leadership training on breakthrough thinking approaches. This created an environment in which staff felt empowered to innovate.

The sense of the role within community (i.e., feelings of responsibility toward the community for advancing or protecting a particular value) was also referenced as a factor driving innovation. A local government body (F) emphasised the importance of their role in ensuring a liveable community, driving policy innovation for regulation of residential development. Similarly, a water-sector entity highlighted the extent of their influence in the community as a force for change, and noted this as a driving force behind policy innovation extending their role beyond a water-only focus to further the goal of 'best community value' (BCE).

\subsubsection{Resources Mobilised in Innovation}

In recounting past experiences of successful policy innovation, stakeholders interviewed highlighted a range of resources mobilised to achieve their innovation aims. Resources mentioned included authority, legitimacy and social capital, in addition to more tangible resources, such as information and expertise.

Authority (i.e., the legitimately recognised right to make decisions) was mobilised either through the authority conferred upon senior public sector managers in public organisations or through the directions and priorities provided by the state government Minister. Examples of the former included the creation of a new energy and greenhouse gas focused position within a water sector entity (K), the creation of a new planning policy within local government $(\mathrm{F})$, a shift in asset renewals approach by an energy distribution entity $(\mathrm{H})$ and the development of a new approach to accounting for the economic benefits of water efficiency (Q). The ability to leverage authority to innovate in response to changing context was provided, in all cases, by the fact that the role of each actor was formally recognised as having the power to make such decisions (i.e., water network management, local government planning regulation, energy network management and water security planning). In case $\mathrm{P}$, advocacy by the stakeholder was successful in eliciting direction from the responsible state government Minister to support changes to residential building regulation.

Legitimacy (i.e., action viewed as acceptable due to being consistent with the values and expectations of the greater environment) was also leveraged in a number of cases. This was noted in the form of action in line with community expectations expressed through local council (F and I) and through consultation with industry networks supported by transparent and accountable decision-making processes (J).

Social capital was leveraged in several cases. Networks played a strong role, including interorganisational knowledge sharing and collaboration (I, A and M), stakeholder engagement (F) and the building of cross-sector alliances (B). A local government actor noted the development and provision of a free tool for industry practitioners (particularly vulnerable/low skill stakeholders) as important in building trust and support for new policy (F). This was coupled with relationship building and consultation with key industry stakeholders to understand and address concerns, building transparency and trust to support new policy. The sharing of research outcomes and information between networks was particularly important for nongovernment actors (A, I and M), used as an 
evidence base to underpin new policy approaches. A water-sector entity (B built on their standing as an actor with strong community relationships to build alliances with other essential service providers (telecommunications, energy), driving new approaches to integrated service delivery.

Tangible resources leveraged included skills and expertise (J), and information exchange. Two stakeholders in government entities referenced the importance of expertise in their ability to anticipate external trends and pro-actively develop policy 'in the background', to be ready when external context (e.g., government priorities) opened up opportunities for action to innovate.

\subsubsection{Strategies for Mobilising Resources}

Strategies employed by stakeholders in instigating change included a focus on flows of information, including the commissioning of expert consultant research and advice, internal education, and advocacy and networking.

Research and expert advice sought (D, I and Q) took the form of economic studies on the expected impact of technology change (e.g., solar PV and battery storage) in households and businesses. These included studies on the potential costs and benefits for households (D), and capital cost affordability issues (I). Economic studies were also undertaken to support cost-benefit studies for water efficiency strategies, by defining the economic value of water retained in storages $(Q)$. Sources of external research and expert advice included consultants, and research partnerships with universities.

In addition to the commissioning of external research, ongoing internal research was also employed $(\mathrm{D}, \mathrm{J}$ and $\mathrm{N})$ to gather information on emerging trends. These included residential sector trends and technology availability (D), and emerging social issues, such as energy hardship and increasing gas prices (J). Internal research was also employed to better define the impacts of household energy access and use on health and well-being $(\mathrm{N})$. Outcomes of such internal research were employed to forecast emerging opportunities in the external environment and focus the development of new policy initiatives. Internal education was also employed by multiple stakeholders (D and I) to build technical capability around emerging technologies, impacts and potential solutions.

Several stakeholders (A, D and P) engaged in advocacy and networking (A-membership; $\mathrm{D}$-state government budget and strategy processes; $\mathrm{P}-$ key decision makers) to garner support for their initiatives. This included building connections between key decision makers to aid integration in urban planning (i.e., energy networks planners and town planners) at critical design stages (A) and advocacy to members/constituents (A). State government strategy and budget-development processes were also targeted (D), through provision of expert advice (drawing on research and highlighting past successes). Relationships with powerful decision makers were leveraged to garner support for policy initiatives $(\mathrm{P})$.

\subsection{Theme 3-Perspectives on Improved Household WRE Management}

\subsubsection{Perceived Opportunities in Water-Related Energy Management}

Respondents noted opportunities in WRE management in several distinct activities, including (i) consumer education and advocacy, (ii) development of standards, (iii) opportunities for participation in electricity networks and markets (including distributed generation), and (iv) reframing organisational boundaries.

Consumer education and advocacy was raised primarily in the context of behaviour change in water end-use activities (B, D, F, I, J and O) and technology choice (H, D and F). Several participants were of the view that the energy impacts of water use are currently poorly understood and that consumers generally lack awareness of the water-energy linkage, and therefore consumer education would be beneficial to inform better consumer choices. The addition of energy savings information was noted as likely to be beneficial in bolstering water-saving arguments. It was suggested that campaigns linked to price/affordability and 'gas shortage'/energy crisis issues are likely to be more potent drivers than efficiency, as these issues are currently highly politicised and more relevant for consumers. A key 
barrier to the success of education and advocacy approaches was noted in the absence of a strong 'crisis' (such as a drought) to drive action-it was suggested that greenhouse gas emissions and climate change impacts are too abstract to motivate behaviour change. Affordability and gas shortage were therefore suggested as likely more effective motivating 'crises'. Another barrier noted, however, was the short-term benefits of behaviour change impacts on affordability, as distributors and retailers would likely respond to reduced revenue by raising fixed tariffs to cover their costs. Equity issues were also raised in relation to full volumetric charging approaches, with low-income and vulnerable houses likely to have less control over quality of housing and appliances (due to tenancy issues and capital investment required for new stock).

Standards were put forward as an opportunity to influence the design phase of residential buildings, which was seen as a significant gap in current WRE management. Several participants (F, L, H, M and N) noted that many of the most significant opportunities to influence WRE use were in the selection and layout of building services, but that the impact of this is not currently considered or actively designed for. Furthermore, a key barrier to better selection and design of building services was noted in the separation of CAPEX (i.e., capital expenditure, occurring during the construction phase of a building) and OPEX (i.e., operational expenditure, occurring during use/occupancy of a building) impacts—with developers/builders making key decisions which would affect the long-term OPEX of residents, but with no incentive to design for operational efficiency, as OPEX does not impact them; instead, it is driven in design choice by CAPEX considerations only. (Similar issues exist in the landlord/tenant divide). It was suggested that plumbing and building standards, building codes and development approvals (including associated scorecard tools) could intervene to target this issue more specifically.

Standards were also proposed in relation to consumer information, in the form of standardised requirements for information on WRE use in consumer bills $(\mathrm{H})$.

The third key opportunity raised was the ability to participate in electricity markets (A, E, K, L and N). A push toward all-electric homes was an issue frequently raised (E, K, L and N). This shift is anticipated due to the increasing prevalence of grid-connected renewable energy sources (e.g., solar and wind), both before (i.e., in the network) and behind the meter (i.e., household), which will make electricity less greenhouse gas intensive than natural gas and likely more economic in the context of recent gas shortages in Victoria. The potential for water systems to aid in peak load management and network stabilisation was raised, by using hot water systems as battery energy storage to smooth household demand ( $\mathrm{A}, \mathrm{K}, \mathrm{L}$ and $\mathrm{N}$ ) and to stabilise energy networks ( $\mathrm{L}, \mathrm{K}$ and $\mathrm{N})$. The rising trend in 'internet of things' type management of household appliances was highlighted as a key enabling factor in these management approaches, relating to the all-electric home trend. The potential for excess household PV energy generation to be on-sold/transferred to water utilities for use in energy intensive manufactured water (e.g., desalination) was also noted (E; see paragraph below for detail). Further, one respondent $(\mathrm{K})$ highlighted the possibility of water utilities partnering with energy distributors to use water networks as energy network storage (e.g., pumped hydro), to assist with energy network stabilisation.

Stakeholders also highlighted opportunities at the macro level, in the form of shifting system goals or paradigms (E and $\mathrm{G}$ ). Both stakeholders challenged traditional approaches to defining the 'value' of policy outcomes in water and energy management. Stakeholder E noted that WRE use was not in itself a problem, but rather the fact that the energy being used contributes to greenhouse gas emissions; similarly, with the advent of alternative supplies such as desalination, water use may not necessarily need to be as constrained for water security purposes if such alternative supplies are generated using renewable energy sources. This stakeholder put forward the possibility of a water utility investing in urban development, by engaging in installation and management of distributed renewable energy generation (such as rooftop solar PV with battery storage) in new residential developments. Ownership and management of the energy source would allow the water utility to access renewable energy to run increasingly energy-intensive water supplies, while simultaneously providing low-cost energy 
to the community. This stakeholder argued that pursuit of such approaches would require decision making on a basis of seeking 'best value solutions', as opposed to traditional 'least cost solutions'. Existing examples of similar undertakings by other water entities were provided, including investment in the development of parklands in a disused-water infrastructure corridor to contribute to both community amenity and water quality protection, which was undertaken in response to community priorities following Ministerial approval. The stakeholder interviewed (E) highlighted that under current arrangements, such approaches challenge state government economic regulation given that these activities fall beyond the regulated mandate of water utilities, and require explicit sign-off from the responsible government Minister. It was noted that the peak industry body for water supply services is in the process of developing papers on value, exploring whether water corporations should be expanding their value proposition beyond core water and sewer services, and that the recent state water strategy (Water for Victoria) supports a 'shared value' approach.

\subsubsection{Perceived Barriers to Water-Related Energy Management}

Stakeholder views on likely barriers to WRE management included (a) complexity challenges, (b) fragmented institutional arrangements and (c) lack of a strong common 'crisis' to motivate consumer behaviour change.

Complexity challenges were raised in the context of information needs and skill requirements. The lack of available water-energy end-use data was raised by several stakeholders ( $D, L$ and $M)$. It was noted that fragmentation of water-energy responsibilities results in a lack of 'critical mass' on the part of any one stakeholder with respect to motivation to take the lead on research into cross-cutting issues ( $\mathrm{M}$ and $\mathrm{Q})$. Motivation aside, stakeholders highlighted the complexity of gathering such data and the corresponding cost issues, stemming from the fact that water and energy end use are typically the concerns of separate stakeholders, and consequently it can be difficult for a single stakeholder to justify increased time or costs associated with collecting data beyond the scope of their role $(C, D$, $\mathrm{J}$ and $\mathrm{Q}$ ). The physical complexity involved in data monitoring for water-energy interactions was also noted as a significant factor driving costs of data collection for water-energy interactions (D). Such data challenges, set against the high level of data integrity required by existing energy-savings incentives programs (such as Renewable Energy Certificates) to claim on the energy saved through water efficiency measures, were raised as historically observed and continuing barriers to potential WRE management approaches (L).

Complexity issues were also highlighted in terms of the increased sophistication in skills required for policymakers, industry tradespeople and consumers, to understand and manage combined water-energy impacts (F, G, L and M). Water-energy impacts require an understanding of water-use issues, impacts and/or technologies to be combined with an understanding of energy (i.e., solar $\mathrm{PV} /$ thermal, gas and/or electricity) use issues, impacts and technologies. In Australia, water and energy are typically the focus of distinct trades (e.g., plumber, gasfitter and electrician), distinct policy considerations and messaging. Understanding of water-energy interactions and trade-offs requires an expanded and complex base of knowledge, skills and analysis tools.

Fragmentation of responsibilities, and subsequent sharing of costs and benefits of WRE efficiency approaches, was highlighted as a barrier in a number of contexts: water and energy supplier versus end-user roles; energy distribution networks versus energy retailer roles; and developer/landlord versus tenant roles.

Fragmentation between energy distribution and supply entities and the energy consumer was raised by an energy distribution network entity (A). They commented that, although the outcomes of WRE management initiatives would benefit them (in terms of greater control over network demands), they did not have the direct relationship with the consumer required to engage in such approaches, and that the energy retailers with the necessary consumer relationships would see less benefit in the outcomes. Similarly, multiple stakeholders (B, C and G) highlighted the potentially mixed motivations 
for a supply entity to encourage end-use efficiency due to the likely impact of reduced revenue through volumetric charging.

Fragmentation in capital and operating expenditure and savings between property owners (developers and landlords) and tenants was highlighted as a likely barrier to WRE management approaches in residential design, construction and appliance choice ( $\mathrm{M}$ and $\mathrm{O})$. This was raised in relation to the end-user (tenant) receiving the longer-term benefits of water-related efficiency investments in terms of reduced water and/or energy operating costs, with the developer or landlord bearing the impact of the capital investment and likely no share of the operational savings. This issue is not unique to WRE management, and it has previously been noted as a barrier to water and/or energy efficient design, but any increased complexity due to 'water-related energy efficient' design would likely exacerbate the issue.

Fragmentation in institutional roles was raised in the context of separation in water and energy management, leading to both a lack of motivation and difficulty in justifying work beyond the core scope of a stakeholder's role (C, D, J and Q), as discussed above, under complexity challenges related to information needs.

Finally, the lack of a clear driver or 'crisis' focus for behaviour change was highlighted by several stakeholders as a potential barrier to WRE management (F, H and L). It was noted that, in the experience of these stakeholders, efficiency arguments alone were not successful in motivating changes in consumer behaviour, and that successful examples had all been associated with a clear crisis such as a drought.

\section{Discussion}

\subsection{Common Goal-Setting for Transition Management toward Water-Related Energy Management}

A core principle of transition management is the setting of a common vision or goal to guide transitions. Those key actors with an interest in household WRE end use who were interviewed for this project displayed a diversity of organisational goals and purposes (Tables 3 and 4). These spanned environmental protection, emissions reduction, resource efficiency, security of supply and consumer protection. In general, energy-sector stakeholders showed a dominant focus on emissions reduction and consumer impacts (cost of living). In contrast, water-sector stakeholders showed a dominant focus on security of supply and cost of living. Finally, residential building and building-services sector stakeholders were primarily motivated by greenhouse gas management and consumer resource efficiency, relating to residential amenity and cost of living. If a common goal was to be set for all these sets of stakeholders to guide a transition toward improved WRE management, a focus on consumer impacts could be a common issue of interest with the potential to achieve buy-in from stakeholders across these sectors. This might be achieved through a focus on cost of water and/or energy services (i.e., tariffs or volumetric usage), or through a focus on consumer amenity (e.g., thermal comfort and water/energy 'productivity'). However, it was highlighted that there are potential disadvantages of a narrow focus on household costs solely by reducing consumer usage volumes. Stakeholder $(G)$ noted that such approaches are likely to lead to backlash through upward market pricing pressures as water and/or energy suppliers seek to cover their business operating costs, and thereby perhaps undermine consumer financial outcomes in the longer term.

\subsection{Insights for Institutional Entrepreneurship for Water-Related Energy Management Policy}

This paper argues that, within a transitions management framework, intervention at niche level offers opportunities to influence the direction of a transition by creating favourable conditions for niche emergence (as discussed in Section 1.2.3). Water and energy stakeholders in Victoria were interviewed to explore past successful examples of policy innovation (Section 2.3.2), drawing on theory from institutional entrepreneurship to define key factors for enabling conditions in the form of enabling 
context and resources mobilised (defined in Table 2). Common themes which were identified in interview findings included the following:

- Enabling conditions:

$-\quad$ Change in government policy/priority;
$-\quad$ Consumer/community attitudes;
$-\quad$ Development of industry norms.

- $\quad$ Resources mobilised:

- Social capital/community support/strong relationships;

- Information flows/consumer education;

- Legitimacy.

Stakeholder perspectives on opportunities for improved household WRE management were also sought (Section 3.3.1). Key medium-term opportunities noted included consumer education and advocacy around water-energy impacts, and the development of residential building standards to better manage the selection and layout of building water-energy services during the design phase.

Insights for potential niche policy innovations toward improved WRE management can by drawn by considering the findings on favourable conditions for niche emergence, in conjunction with stakeholder perspectives on policy opportunities, as outlined above. These considerations are summarised in Figure 1 and further discussed below.

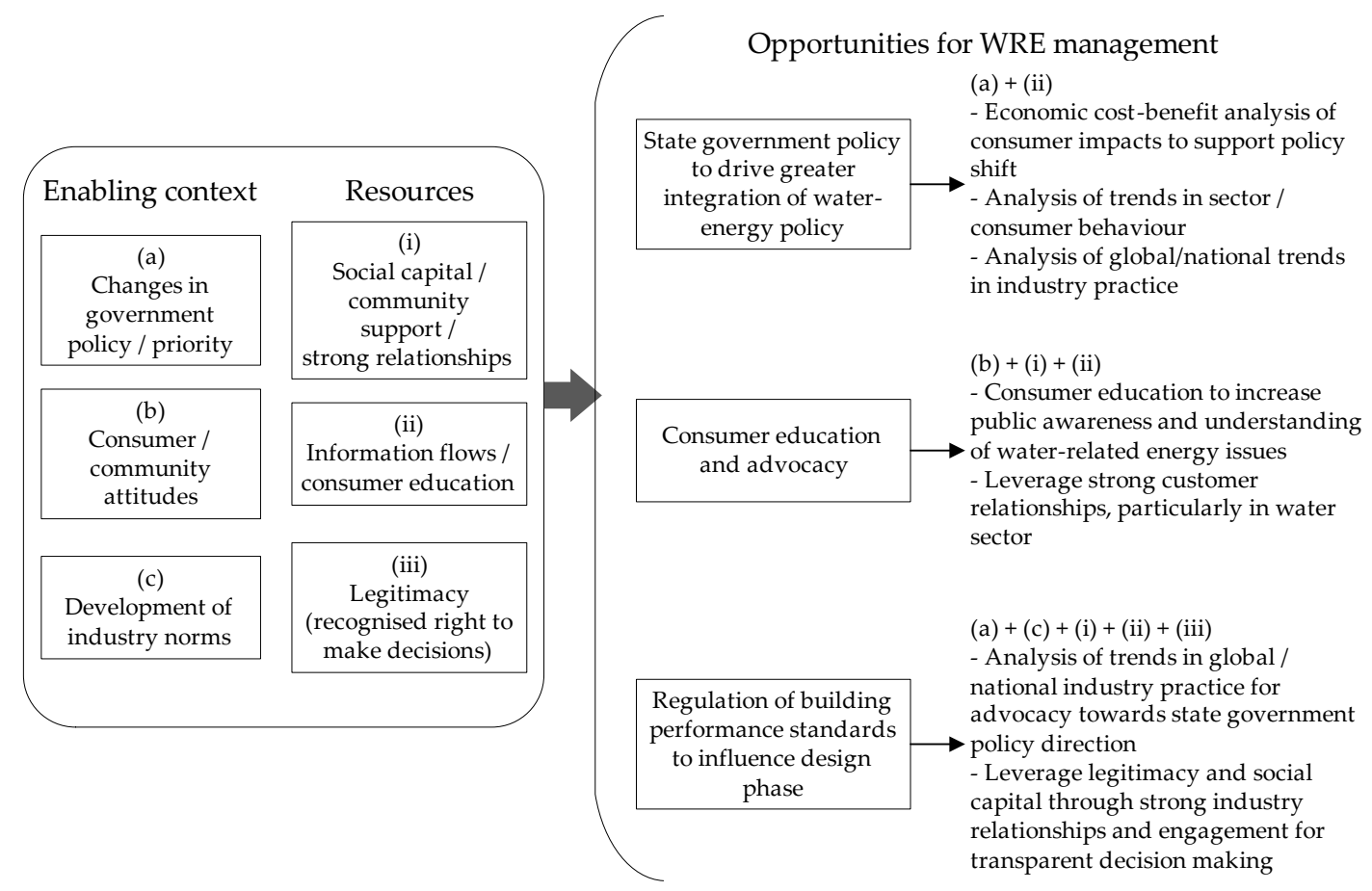

Figure 1. Summary of insights for water-related energy management policy.

Shifts in government priorities and/or policy direction were noted most frequently by stakeholders interviewed as the contextual driver that facilitated examples of policy entrepreneurship. The importance of government-level shifts is echoed within stakeholder perceptions of potential opportunities in WRE management, with multiple respondents suggesting that any move toward greater integration of water- and energy-use management would need to be driven by state government (L, N and P). Three main reasons were given: (a) state government is best placed to have a holistic 
view of cross-cutting issues across water-energy siloes, particularly with responsibility for water and energy issues falling under the same department in Victoria; (b) that state government would have the most interest in seeing solutions to cross-cutting issues (such as WRE) and consequently in creating an environment to implement those solutions (N); and (c) that state government has the authority to develop policies and set direction to create such an environment $(\mathrm{P})$. Based on the past examples of successful policy entrepreneurship given by stakeholders, the kind of information which might support such a shift includes economic cost-benefit analysis of consumer impacts and analysis of trends in consumer and/or sector behaviour (D), and global/national trends in industry practice (P).

Consumer education was also highlighted by many stakeholders interviewed as a strong opportunity for WRE management. It was noted that water utilities are likely to have the strongest customer relationships $(\mathrm{O})$ and are therefore well placed to drive such initiatives. Another important factor here is the perceived role of consumer/community attitudes and support as a key resource mobilised in past stakeholder experiences of policy innovation (e.g., stakeholders F and I). Increasing information flows and education for consumers has the potential to raise public awareness and understanding of WRE issues, which in turn has significant potential to shape community concerns, building a political resource which can be mobilised for entrepreneurship activities. This feedback loop (information-awareness-political concern) has the potential to lead to longer-term transition outcomes. However, stakeholders also noted that an essential condition for such an approach is the existence of a clear 'crisis' to drive consumer interest in engaging with information and education campaigns $(\mathrm{F}, \mathrm{H}$ and L). In the absence of such a driver, the success of information and education campaigns is likely to be limited. It was suggested that the recent 'gas shortage' crisis and growing concern about energy affordability could potentially become motivating issues.

Finally, performance standards were also put forward as an area of opportunity by a number of stakeholders interviewed. Several noted that the building design stage is where consideration of operational water-energy impacts can be most influenced, and that there is currently a big challenge to overcome lack of integration of water/energy considerations in this design stage (e.g., location of hot water system with respect to end-use water services). Building-sector stakeholders (e.g., P and F) have a strong regulatory influence at this stage in the form of the building code and residential development approvals, which address building design aspects. These stakeholders reported experience of policy innovation in the context of shifting government priorities $(P)$ and development of industry norms $(F)$. Information played a key role in the form of advocacy toward state government key decision makers based on global/national trends $(\mathrm{P})$, as did the leveraging of strong social capital and legitimacy $(\mathrm{F})$ (built through engagement and transparent processes).

Despite the current gap in integrated water-energy considerations in building standards and regulation, the building sector is seen as an area for achieving greater integration of water-energy considerations, with water and energy impacts both included in the same development approval processes and building codes. This might be attributed to the ways in which the residential envelope itself drives considerations of operational resource use as a whole, as a function of the set of services provided within a residence. Thus, an opportunity for improved WRE management may arise through further consideration of (a) an identified gap in consideration of integrated water-energy impacts and (b) an existing confluence of water and energy regulation. This opportunity would assist in overcoming some of the barriers identified in the CAPEX/OPEX divide.

Complexity of data and skill requirements and the fragmentation of responsibilities, costs and benefits were two of the most commonly identified barriers to progress in WRE management. Interaction between these issues was also highlighted, with fragmentation of water-energy responsibilities noted as a barrier to collecting the complex data required to account for water-energy interaction (due to an inability to justify increased expenditure on issues beyond the core focus of a water/energy/supply/use focused role). The development of benefits-sharing frameworks and support for interorganisational collaboration may also have the potential to contribute significantly in this context. 


\section{Conclusions}

This study explored enabling conditions for policy entrepreneurship for improved water-related energy management. This was achieved through a focus on identifying the objectives of key stakeholders, in regard to household water and/or energy management, and their past experiences of policy change contexts and resources. Stakeholder objectives were found to vary across sectors, but cost of living was a common theme, and may therefore offer a basis for developing a shared vision for a transition toward improved household WRE management. State government policy and/or priority changes were the most common context referenced as underpinning stakeholders' past experiences of policy innovation. Strategies which had been successfully employed for policy innovation focused primarily on flows of information, including cost-benefit analysis (both economic and non-economic cost), the identification of emerging sectoral trends, and advocacy and networking to garner support.

Key medium-term opportunities for household WRE management were noted by stakeholders in consumer education and advocacy around water-energy impacts and the development of residential building standards to better manage the selection and layout of building services. These opportunities were seen to be tempered by several barriers in the form of complex information needs and skills required to understand water-energy impacts (for industry and consumers alike), and fragmented approaches to cost-benefit between (a) supply versus use orientation, (b) distribution of services versus retail supply and (c) residential developers versus residents.

These findings suggest that, to create an enabling environment for policy innovation for improved household water-related energy management, a focus on the following may be beneficial:

- Policy framing and data analysis focused on impacts of WRE use on household cost of living as a unifying vision across key stakeholders and sectors;

- Development of 'shared value' frameworks to better distribute the costs and benefits of WRE management;

- Advocacy to shift state government policy priorities to a clearer focus on integration of water- and energy-management considerations, or anticipation of emerging government priorities and the pre-emptive demonstration of the relevance of WRE management to those priorities;

- Collection of data to support cost-benefit analysis of the expected impacts of household WRE management policy, in both economic and non-economic (e.g., health and well-being) terms;

- Data analysis to support selection and layout of water and energy service infrastructure in residential buildings for improved WRE outcomes;

- Development of tools and materials to improve literacy in, and visibility of, household water-energy interactions.

Author Contributions: Conceptualization, A.B., B.H., P.L. and S.K.; methodology, A.B., B.H. and P.L.; formal analysis, A.B.; investigation, A.B.; resources, S.K.; data curation, A.B.; writing-original draft preparation, A.B.; writing-review and editing, S.K., P.L. and B.H.; supervision, S.K., P.L. and B.H.; project administration, S.K.; funding acquisition, S.K. All authors have read and agreed to the published version of the manuscript.

Funding: This research was funded by the Smart Water Fund in addition to the Australian Research Council's Linkage Projects funding scheme, project number LP120200745.

Acknowledgments: The authors wish to acknowledge the generosity of all of the research participants who gave their time to be a part of this study.

Conflicts of Interest: The authors declare no conflicts of interest.

\section{References}

1. Kenway, S.J.; Scheidegger, R.; Larsen, T.A.; Lant, P.; Bader, H.-P. Water-related energy in households: A model designed to understand the current state and simulate possible measures. Energy Build. 2013, 58, 378-389. [CrossRef]

2. United Nations. New Urban Agenda. In Proceedings of the United Nations Conference on Housing and Sustainable Urban Development (Habitat III), Quito, Ecuador, 25 January 2017. 
3. United Nations. World Population Prospects 2019: Highlights; Department of Economic and Social Affairs, Population Division: New York, NY, USA, 2019.

4. Artioli, F.; Acuto, M.; McArthur, J. The water-energy-food nexus: An integration agenda and implications for urban governance. Polit. Geogr. 2017, 61, 215-223. [CrossRef]

5. United Nations. Transforming our world: the 2030 Agenda for Sustainable Development; UN General Assembly: New York, NY, USA, 2016.

6. Hightower, M.; Pierce, S.A. The energy challenge. Nature 2008, 452, 285-286. [CrossRef]

7. King, C.W.; Stillwell, A.S.; Twomey, K.M.; Webber, M.E. Coherence Between Water and Energy Policies. Nat. Resour. J. 2013, 53, 117-215.

8. Al-Saidi, M.; Elagib, N.A. Towards understanding the integrative approach of the water, energy and food nexus. Sci. Total Environ. 2017, 574, 1131-1139. [CrossRef] [PubMed]

9. Rothausen, S.; Conway, D. Greenhouse-gas emissions from energy use in the water sector. Nat. Clim. Chang. 2011, 1, 201-219. [CrossRef]

10. Hussey, K.; Pittock, J. The Energy-Water Nexus: Managing the Links between Energy and Water for a Sustainable Future. Ecol. Soc. 2012, 17, 9. [CrossRef]

11. Scott, C.A.; Pierce, S.A.; Pasqualetti, M.J.; Jones, A.L.; Monts, B.E.; Hoover, J.H. Policy and institutional dimensions of the water-energy nexus. Energy Policy 2011, 39, 6622-6630. [CrossRef]

12. Pittock, J.; Hussey, K.; McGlennon, S. Australian Climate, Energy and Water Policies: Conflicts and synergies. Aust. Geogr. 2013, 44, 3-22. [CrossRef]

13. Teschner, N.; McDonald, A.; Foxon, T.J.; Paavola, J. Integrated transitions toward sustainability: The case of water and energy policies in Israel. Technol. Forecast. Soc. Chang. 2012, 79, 457-468. [CrossRef]

14. Lam, K.L.; Kenway, S.J.; Lant, P.A. City-scale analysis of water-related energy identifies more cost-effective solutions. Water Res. 2017, 109, 287-298. [CrossRef] [PubMed]

15. Cook, S.; Hall, M.; Gregory, A. Energy Use in the Provision and Consumption of Urban Water in Australia: An Update; Water Services Association Australia: Melbourne, Australia, 2012.

16. Lam, K.L.; Lant, P.A.; O'Brien, K.R.; Kenway, S.J. Comparison of water-energy trajectories of two major regions experiencing water shortage. J. Environ. Manag. 2016, 181, 403-412. [CrossRef] [PubMed]

17. Kenway, S.J.; Priestley, A.; Cook, S.; Seo, A.; Inman, M.; Gregory, A. Energy Use in the Provision and Consumption of Urban Water in Australia and New Zealand; CSIRO Water for a Healthy Country Flagship: North Ryde, Australia, 2008.

18. Binks, A.N.; Kenway, S.J.; Lant, P.A.; Head, B.W. Understanding household water-related energy use and identifying physical and human characteristics of major end uses. J. Clean. Prod. 2016, 135, 892-906. [CrossRef]

19. Huitema, D.; Meijerink, S. Realizing water transitions: The role of policy entrepreneurs in water policy change. Ecol. Soc. 2010, 15, 10. [CrossRef]

20. Leca, B.; Battilana, J.; Boxenbaum, E. Agency and Institutions: A Review of Institutional Entrepreneurship; Harvard Business School: Boston, MA, USA, 2008.

21. Geels, F.W.; Elzen, B.; Green, K. General Introduction: System Innovation and Transitions to Sustainability. In System Innovation and the Transition to Sustainability; Elzen, B., Geels, F.W., Eds.; Edward Elgar Publishing: Northampton, MA, USA, 2004; pp. 1-16.

22. Loorbach, D.; Frantzeskaki, N.; Thissen, W. Introduction to the special section: Infrastructures and transitions. Technol. Forecast. Soc. Chang. 2010, 77, 1195-1202. [CrossRef]

23. Geels, F.W. Technological transitions as evolutionary reconfiguration processes: A multi-level perspective and a case-study. Res. Policy 2002, 31, 1257-1274. [CrossRef]

24. Loorbach, D.; Frantzeskaki, N.; Huffenreuter, R.L. Transition management: Taking stock from governance experimentation. J. Corp. Citizsh. 2015, 58, 48-66. [CrossRef]

25. Geels, F.W. Multi-Level Perspective on System Innovation: Relevance for Industrial Transformation. In Understanding Industrial Transformation—Views from Different Disciplines; Olshoorn, X., Wieczorek, A.J., Eds.; Springer: Dordrecht, The Netherlands, 2006; pp. 163-186.

26. Meadowcroft, J. What about the politics? Sustainable development, transition management, and long term energy transitions. Policy Sci. 2009, 42, 323-340. [CrossRef]

27. Bettini, Y.; Brown, R.R.; de Haan, F.J.; Farrelly, M. Understanding institutional capacity for urban water transitions. Technol. Forecast. Soc. Chang. 2015, 94, 65-79. [CrossRef] 
28. Loorbach, D. Transition Management for Sustainable Development: A Prescriptive, Complexity-Based Governance Framework. Governance 2010, 23, 161-183. [CrossRef]

29. Rotmans, J.; Loorbach, D. Managing Transitions for Sustainable Development. In Understanding Industrial Transformation; Springer: Dordrecht, The Netherlands, 2006; pp. 187-206.

30. Smith, A.; Stirling, A. The politics of socio-ecological resilience and sustainable socio-technical transitions. Ecol. Soc. 2010, 15, 11. [CrossRef]

31. Smith, A.; Voss, J.P.; Grin, J. Innovation studies and sustainability transitions: The allure of the multi-level perspective and its challenges. Res. Policy 2010, 39, 435-448. [CrossRef]

32. Markard, J.; Suter, M.; Ingold, K. Socio-technical transitions and policy change-Advocacy coalitions in Swiss energy policy. Environ. Innov. Soc. Transit. 2016, 18, 215-237. [CrossRef]

33. Markard, J.; Raven, R.; Truffer, B. Sustainability transitions: An emerging field of research and its prospects. Res. Policy 2012, 41, 955-967. [CrossRef]

34. Voß, J.-P.; Smith, A.; Grin, J. Designing long-term policy: Rethinking transition management. Policy Sci. 2009, 42, 275-302. [CrossRef]

35. Berkhout, F.; Smith, A.; Stirling, A. Socio-Technological Regimes and Transition Contexts. In System Innovation and the Transition to Sustainability: Theory, Evidence and Policy; Elzen, B., Geels, F.W., Eds.; Edward Elgar: Cheltenham, UK, 2004; pp. 48-75.

36. Hughes, E.C. The ecological aspect of institutions. Am. Sociol. Rev. 1936, 1, 180-189. [CrossRef]

37. Khalil, E.L. Organizations versus Institutions. J. Inst. Theor. Econ. 1995, 151, 445-466.

38. Garud, R.; Hardy, C.; Maguire, S. Institutional Entrepreneurship as Embedded Agency: An Introduction to the Special Issue. Organ. Stud. 2007, 28, 957-969. [CrossRef]

39. Strang, D.; Sine, W.D. Interorganizational Institutions. In Companion to Organizations; Baum, J., Ed.; Blackwell: Hoboken, NJ, USA, 2002; pp. 497-519.

40. Dacin, T.M.; Goodstein, J.; Scott, W.R. Institutional theory and institutional change: Introduction to the special research forum. Acad. Manag. J. 2002, 45, 45-56. [CrossRef]

41. Greenwood, R.; Suddaby, R.; Hinings, C.R. Theorizing change: The role of professional associations in the transformation of institutionalized fields. Acad. Manag. J. 2002, 45, 58-80.

42. Maguire, S.; Hardy, C.; Lawrence, T.B. Institutional entrepreneurship in emerging fields: HIV/AIDS treatment advocacy in Canada. Acad. Manag. J. 2004, 47, 657-679.

43. Tolbert, P.S.; Zucker, L.G. Institutionalization of institutional theory. In Handbook of Organizational Studies; Clegg, S., Hardy, C., Eds.; Sage: London, UK, 1996; pp. 175-190.

44. Binks, A.N.; Kenway, S.J.; Lant, P.A. The effect of water demand management in showers on household energy use. J. Clean. Prod. 2017, 157, 177-189. [CrossRef]

45. Robson, C. Real World Research: A Resource for Social Scientists and Practitioner Researchers; Blackwell: Hoboken, NJ, USA, 2002.

(C) 2020 by the authors. Licensee MDPI, Basel, Switzerland. This article is an open access article distributed under the terms and conditions of the Creative Commons Attribution (CC BY) license (http://creativecommons.org/licenses/by/4.0/). 